\title{
Characterization of Thyroid-Stimulating Blocking Antibodies That Appeared During Transient Hypothyroidism After Radioactive lodine Therapy
}

\author{
Annie W.C. Kung, ${ }^{1}$ K.S. Lau, ${ }^{1}$ and L.D. Kohn ${ }^{2}$
}

Hypothyroidism after radioactive iodine (RAI) therapy for Graves' disease can be transient or permanent. The cause for early transient hypothyroidism is unknown. We evaluated 11 patients who developed transient hypothyroidism within 6 months of RAI and 12 who remained euthyroid after RAI. Approximately equal numbers of patients in each group had thyroid-stimulating antibody (TSAb) that increased cyclic adenosine monophosphate (cAMP) levels in Chinese hamster ovary (CHO) cells transfected with the recombinant human thyrotropin receptor (TSHR) (WT cells). Approximately equal numbers of patients from both groups had an increase in TSAb activity post-RAI. All TSAbs had their dominant functional epitope on the N-terminus of the TSHR extracellular domain, requiring residues $90-165$ for activity because they, but not TSH, completely lost stimulating activity in a receptor chimera, wherein TSHR residues 90-165 were substituted by equivalent residues of the lutropin/choriogonadotropin receptor (LH/CGR). Although equal numbers of patients in both groups had thyrotropin-binding inhibiting immunoglobulin activity (TBII), as measured by radioreceptor assay before RAI, patients with transient hypothyroidism had a surge in TBII activity and all except one became positive for thyroid-stimulating blocking antibodies (TSBAb), as measured by inhibition of TSH-stimulated cAMP from WT cells. When immunoglobulin G (IgGs) were epitope-mapped using TSHR/LH-CGR chimeras with different substitutions, 8 hypothyroid subjects had TSBAbs directed against residues 90-165 of the TSHR, as well as TSHR residues 261-370. Two had functional epitopes directed at residues 9-89 as well as TSHR residues 261-370. None of the euthyroid control patients developed TSBAbs and their TBII activity decreased post-RAI. When patients with transient hypothyroidism reverted to a euthyroid state, TSAb was still detectable in 5; however, TBII was present in all and TSBAb, although decreased, was still positive in 9. In summary, RAI therapy was associated with a change in thyroid antibody characteristics in most patients. Additionally, patients with a surge in TBII and the appearance of TSBAb developed transient hypothyroidism after RAI.

\section{Introduction}

$\mathbf{R}$ ADIOACTIVE IODINE THERAPY (RAI) is used as the therapy of choice for hyperthyroidism due to Graves' disease. With better understanding of the safety of RAI, it is even prescribed more frequently for younger patients as the first-line treatment of choice. Hypothyroidism commonly develops after RAI. The incidence of permanent hypothyroidism after RAI increases with time but is largely dependent on the dose of ${ }^{131}$ I administered $(1,2)$. In the majority of cases, hypothyroidism is caused by radiation damage to the thyroid.

Approximately $10 \%$ to $15 \%$ of patients may, however, develop transient hypothyroidism a few months after RAI, but do not require life-long thyroxine $\left(\mathrm{T}_{4}\right)$ replacement therapy. The cause of transient hypothyroidism after RAI was thought to be caused by a short-lived organification defect (3). However, it has been suggested by ourselves and others that the transient development of hypothyroidism could be related to changes in antibody parameters. With the availability of more specific tests for characterization of the antithyroid antibodies, it was observed that RAI could result in alteration of the antibody profiles and that the resulting change in antibody profiles could lead us to a change in the clinical status of the patients $(4,5)$. A transient surge in thyrotropin-binding inhibitory immunoglobulin (TBII) has been seen in patients with Graves' disease (6); however, the TBII

${ }^{1}$ Department of Medicine, The University of Hong Kong, Queen Mary Hospital, Hong Kong.

${ }^{2}$ Cell Regulation Section, Metabolic Diseases Branch, NIDDK, Bethesda, Maryland. 
activity did not correlate with the thyroid-stimulating antibody (TSAb) activity as measured by cyclic adenosine monophosphate (cAMP) release from thyroid cells (7). Recently, Michelangeli et al. (8) reported that hypothyroidism after RAI could be associated with the production of thyroidblocking antibodies but did not further characterize these.

In the present study, we studied patients who developed transient hypothyroidism after a low to moderate dose of RAI, evaluated their thyrotropin receptor (TSHR) antibody profile, and correlated changes in TSHR antibodies with the clinical thyroid status. In order to evaluate the TSHR antibody profiles, we measured TBII activity, thyroid-stimulating TSHR antibodies, and three different types of thyroidstimulating blocking antibodies in each patient's sera. The stimulating and blocking TSHR antibodies were measured using Chinese hamster ovary (CHO) cells transfected with wild-type human TSHR or transfected with several TSHR lutropin/choriogonadotropin receptor (LH/CGR) chimeras: $\mathrm{Mc1}+2$, Mc2, and Mc4. The Mc1 + 2, Mc2, and Mc4 chimeras substitute, respectively, TSHR residues 9-165, 90-165, and 261-370 with equivalent residues of the $\mathrm{LH} / \mathrm{CGR}$. Using this panel, the following functional TSHRAbs can be separately measured (9-17). TBIIs in Graves' patients whose functional epitopes are on the N-terminus of the extracellular domain, which can block TSH activity, and that are directed at TSHR residues $90-165$ or 9-89; TBIIs whose functional epitopes are on the C-terminal portion of the extracellular domain, residues 261-370, which block stimulating TSHR antibodies as well as TSH activity and that are associated with hypothyroidism in patients with idiopathic myxedema or Hashimoto's thyroiditis; stimulating TSHR antibodies whose activity is dependent on the Nterminus of the extracellular domain and are the predominant functional epitope in $95 \%$ of Graves' patients; stimulating TSHR antibodies whose epitope is heterogeneous and involves epitopes other than on the $\mathrm{N}$-terminus (9-165), although their predominant epitope remains on the $\mathrm{N}$-terminus, have been reported to have diagnostic and therapeutic implications in patients receiving methimazole treatment $(10,11)$.

\section{Patients and Methods}

\section{Patients}

The subjects were part of a group of 120 patients recruited to study the factors that determine hypothyroidism after RAI (18). The diagnosis of Graves' disease was based on clinical assessment, a diffuse increased uptake on thyroid scan, and elevated total serum $\mathrm{T}_{4}$ level or free thyroxine index (FTI). The dose of RAI was intended to deliver $80 \mathrm{~Gy}$ to the thyroid gland and was calculated according to the formula of Blomfield et al. (19). The thyroid gland size was estimated by scan using Goodwin's formula (20). Among these 120 patients, 11 subjects who developed transient hypothyroidism were studied. They had low free thyroxine $\left(\mathrm{FT}_{4}\right)$ and elevated TSH within the first 6 months after RAI treatment, but subsequently became and remained euthyroid at 1 year. Sera were taken before RAI, during hypothyroidism, and at euthyroidism. Twelve subjects who received similar RAI therapy during the same period but remained euthyroid afterwards were also studied before, at 6 months, and 12 months after RAI. All patients were followed for at least 5 years and were documented euthyroid by regular thyroid function test monitoring.

\section{Immunoglobulin G preparation}

Sera were stored at $-70^{\circ} \mathrm{C}$ until immunoglobulin G (IgG) preparation. IgGs were extracted by affinity chromatography using protein A-Sepharose CL-4B columns (Amersham Pharmacia, Piscataway, NJ) followed by dialysis. The purity of the IgG preparation was confirmed by documentation of unmeasurable TSH levels.

\section{Thyroid autoantibody assays}

Thyroid-stimulating antibody (TSAb) was determined in purified IgG by measuring cAMP released from Chinese hamster ovary $(\mathrm{CHO})$ cells stably transfected with wild-type human TSHR (WT cells) as described (9-13). In brief, assays were performed in $\mathrm{NaCl}$-free $\mathrm{HBSS}$ containing $20 \mathrm{mmol} / \mathrm{L}$ of HEPES ( $\mathrm{pH}, 7.4$ ), 1\% bovine serum albumin (BSA), of 0.5 $\mathrm{mmol} / \mathrm{L}$ of 3-isobutyl-L-methylxanthine, and $222 \mathrm{mmol} / \mathrm{L}$ of sucrose to make incubations isotonic. Bovine thyrotropin (bTSH), $1 \mathrm{mU} / \mathrm{mL}$ (Sigma, St. Louis, MO), or purified IgG, $1.5 \mathrm{mg} / \mathrm{ml}$, dissolved in $300 \mu \mathrm{L}$ of incubation media and incubated with cells for 2 hours at $37^{\circ} \mathrm{C}$. Supernatants were aspirated and stored at $-20^{\circ} \mathrm{C}$; cAMP released into the medium was measured by RIA. TSAb activity was expressed as the percentage increase in cAMP levels in the experimental IgG relative to pooled IgG from 20 normal individuals.

Thyroid-stimulating blocking antibody (TSBAb) was determined by IgG-induced inhibition of the TSH-stimulated cAMP response to CHO-hTSHR cells (WT cells) as reported previously (10-12). To calculate TSBAb activity, the following formula was used: $100 \% \times\{1-[$ (cAMP accumulation in the presence of TSH and test IgG)/cAMP accumulation in the presence of TSH (1 mIU/L) and normal IgG)]\}. To characterize the blocking activity of the IgG further, the Ig were also evaluated using Mc1 $+2, \mathrm{Mc} 2$, and Mc4 cells. Mc1 +2 cells are $\mathrm{CHO}$ cells transfected with an hTSHR-LH/CGR chimera in which residues 9-165 of TSHR were replaced by residues 101-166 of the LH/CGR. In Mc2 cells, TSHR residues $90-165$ were replaced by residues 91-166 of the LH/CGR. In Mc4 cells, TSHR residues 261-370 were replaced by residues 261-329 of the LH/CGR. In Mc4 cells, TSBAb activity was measured using a TSAb as the stimulator rather than $\mathrm{TSH}$, with otherwise identical calculations.

TBII was determined in patients' sera by inhibition of specific $\left[{ }^{125} \mathrm{I}\right] \mathrm{bTSH}$ binding to porcine thyroid membranes in a radioreceptor assay (RSR, Cardiff, UK). Assay results were expressed in terms of inhibition of TSH binding, calculated as follows: $100 \% \times\{1-$ (labeled TSH specifically bound in the presence of test serum/labeled TSH specifically bound in the presence of normal serum)\}.

Triplicate assays were performed on all samples for antibody assays. The cAMP RIA assays (Incstar Corp., Stillwater, $\mathrm{MN}$ ) were performed in duplicate. The normal ranges in 20 healthy subjects for TBII, TSAb, and TSBAb were $+15 \%$ to $-15 \%, 60 \%-145 \%$, and $-15 \%$ to $+20 \%$, respectively. The determination of TSAB and TSBAb in the same sample was performed in the same assay. The intraassay and interassay coefficients of variance for TBII, TSAb, and TSBAb were $5.0 \%$ and $8.6 \%, 6.0 \%$ and $8.9 \%$, and $9.7 \%$ and $11.6 \%$, respectively. 


\section{Statistics}

Comparisons between hypothyroid patients and euthyroid controls were performed using two-way analysis of variance (ANOVA). Comparison within groups were performed using two-sample $t$ tests or Wilcoxon ranks test depending on the distribution of the data.

\section{Results}

The patients examined in this study were all those who developed transient hypothyroidism during a study of 120 consecutive Graves' patients treated with RAI (9). Control patients were all those in the same study who were euthyroid after RAI. They were of similar age and gender. They had no significant difference in onset of hyperthyroidism, thyroid hormone or TSH levels, levels of thyroglobulin $\mathrm{T}_{\mathrm{C}}$ or thyroid peroxidase (TPO) antibodies, thyroid size, and RAI dose (Table 1). The clinical characteristics of patients who developed transient hypothyroidism or remained euthyroid after RAI and were studied in this report were, therefore, similar. For those with transient hypothyroidism, the mean time to develop hypothyroidism was $4.5 \pm 1.8$ months after RAI. Thus, control patients and those with transient hypothyroidism were evaluated at a similar interval after radioiodine therapy in the assays to follow.

In the patients with transient hypothyroidism, TSAb activity, measured by WT cells was positive in 6 patients before RAI (Fig. 1; Table 2, bold). Eight patients had TBII activity before RAI and one subject had TSBAb (Fig. 1; Table 2 , bold). During transient hypothyroidism, an increase in $\mathrm{TSAb}$ was observed in four subjects (Table 2; starred). All except one subject was positive for TSBAb; and all patients had a surge in TBII titer (Fig. 1; Table 2, starred). At euthyroidism, TSAb was still detectable in five subjects (Table 2 , bold); however, although all patients were positive for TBII and eight subjects were positive for TSBAb, the titers of each had decreased (Table 2, double starred for individuals with significant reduction in blocking TSHRAb and TBII activity at euthyroidism). As a group, significant differences in the median values of TSAb $(p<0.05)$, TSBAb $(p<0.001)$, and TBII $(p<0.0005$, contrast from ANOVA for repeated measures) could be detected in these patients before RAI, during transient hypothyroidism, and at euthyroid state (Table 2).

In the 12 control patients who remained euthyroid after RAI, TSAb measured with WT cells was present in 5 sub- jects before RAI, an approximately equal number as in the patients who would develop transient hypothyroidism (Fig. 1 ; Table 2, bold). Three patients remained positive for TSAb at 6 months and 6 at 12 months (Fig. 1; Table 2, bold). All control subjects were negative for TSBAb throughout the study (Fig. 1; Table 2). Ten control subjects had TBII activity before RAI, but there was no major surge in these activities at 6 or 12 months, comparable to the surge in TBII values in the patients with transient hypothyroidism (Table 2). There was no significant difference in the median values of TSAb, TSBAb, and TBII in these control patients before and after RAI (Table 2).

For those patients with transient hypothyroidism, their median TSBAb and TBII values but not TSAb at the time of transient hypothyroidism as well as during euthyroidism were significantly higher than those values of the control patients taken at a similar time point after RAI (Table 2).

\section{Stimulating TSAbS}

We characterized the stimulating TSAb epitopes in all patients positive for TSAbs at the start of therapy, those with transient hypothyroidism, or their matched euthyroid controls. Overall, the median values for TSAb activity measured in the various cell lines were similar between the two groups (Table 3). There was a complete loss in the ability of the stimulating TSAb to increase CAMP levels in Mc2 cells. Values with significant losses by comparison to wild-type values $(p<0.05)$ are starred (Table 3$)$. Mc2 cells have TSHR residues 90-165 substituted by the homologous LH/CGR residues. Similarly, there was a complete loss of TSAb activity in Mc1 +2 cells, which had TSHR residues 9-165 substituted (Table 3, starred, $p<0.05$ ). Although stimulating TSHRAb activity increased in some patients post-RAI therapy (Table 2 ), epitope mapping did not reveal a significant change in these data.

Thus, the stimulating autoantibodies had the major portion of their functional epitopes directed against the N-terminal portion of the extracellular domain of TSHR and required expression of residues 90-165 of TSHR for their activity. Moreover, in all patients with stimulating TSHR antibodies, the stimulators appeared to have the same characteristics in both control patients and those with transient hypothyroidism.

Of interest, the ability of all the stimulating TSAb to increase cAMP levels in Mc4 cells was similar to that noted in

Table 1. Clinical Characteristics of Patients with Graves' Hyperthyroidism Given Radioactive Iodine (Rai) who Developed Transient Hypothyroidism vs. Paired Control Patients who Remained Euthyroid

\begin{tabular}{lcc}
\hline & Transient hypothyroidism & Euthyroid controls \\
\hline No. of patients (M/F) & $11(3 / 8)$ & $12(3 / 9)$ \\
Mean age (range) (yr) & $48(32-68)$ & $51(36-71)$ \\
Onset of hyperthyroidism (months) & $4.7 \pm 2.3$ & $4.6 \pm 3.1$ \\
Serum FT $(\mathrm{pmol} / \mathrm{L})$ & $64 \pm 37$ & $68 \pm 35$ \\
Serum TSH (mIU/L) & All $<0.03$ & $\mathrm{All}<0.03$ \\
Mean anti-Tg titer (range) & $400(<100-25,600)$ & $400(<100-25,600)$ \\
Mean anti-TPO titer (range) & $6400(<100-25,600)$ & $6400(<100-25,600)$ \\
Estimated thyroid volume (mL) & $38 \pm 27$ & $35 \pm 30$ \\
Radioactive iodine dose (MBq) & $371 \pm 158$ & $386 \pm 179$ \\
\hline
\end{tabular}

$p$ all $=$ not significant.

$\mathrm{FT}_{4}$, free thyroxine; $\mathrm{TSH}$, thyrotropin; $\mathrm{Tg}$, thyroglobulin; $\mathrm{TPO}$, thyroid peroxidase. 


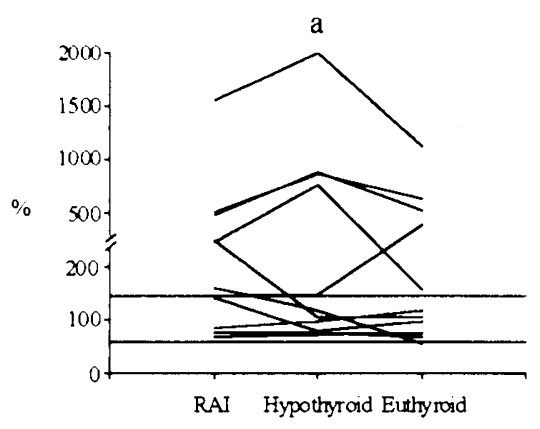

TSAb

b

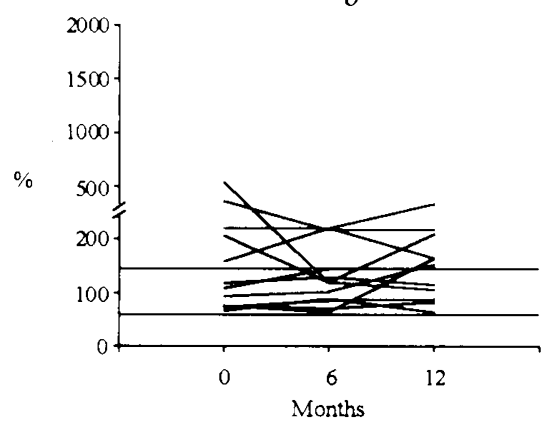

TSBAb
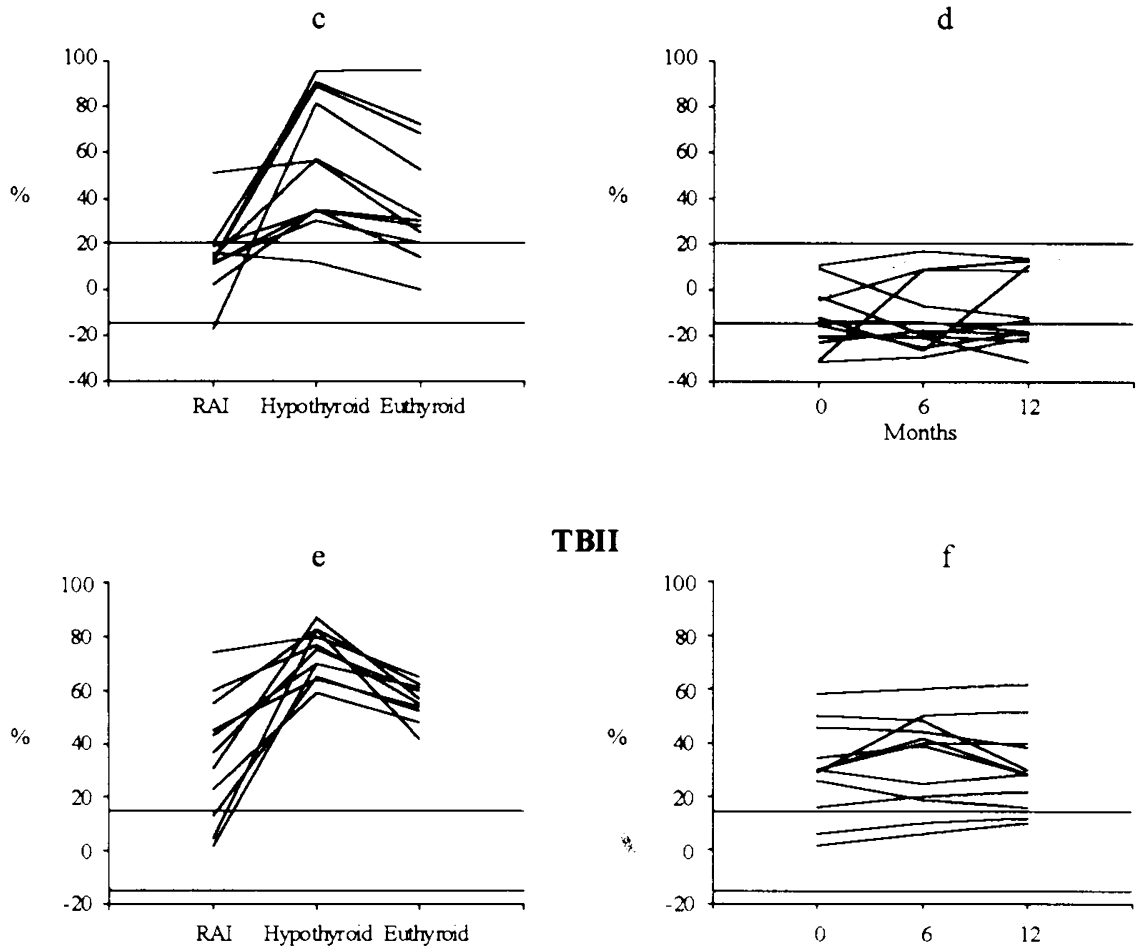

TBII

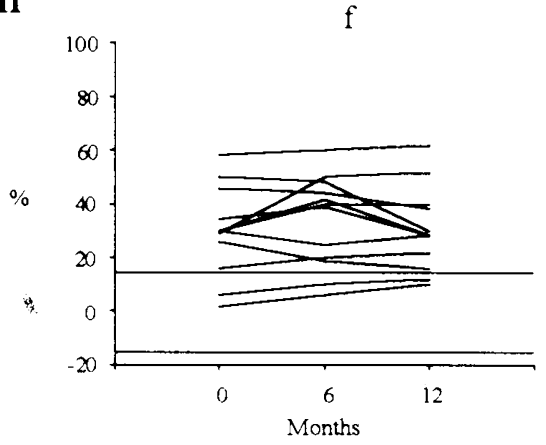

FIG. 1. Thyroid stimulating antibody (TSAb) as measured by cyclic adenosine monophosphate (cAMP) release. Thyroid autoantibodies in patients developing transient hypothyroidism after radioactive iodine (RAI) therapy and in a matched set of patients who remained euthyroid. In Chinese hamster cells $(\mathrm{CHO})$ transfected with the extracellular domain of the thyrotropin receptor (TSHr) (WT cells) $(\mathbf{a}, \mathbf{b})$, Thyroid stimulating-blocking antibody (TSBAb) as determined by inhibition of TSH-stimulated cAMP response by immunoglobulin G (IgG) samples in WT cells (c, d). Thyroid-binding inhibitory immunoglobulin (TBII) as measured by radioreceptor assay $(\mathbf{e}, \mathbf{f})$. The panels show transient hypothyroid subjects before RAI treatment, during hypothyroidism and at euthyroidism $(\mathbf{a}, \mathbf{c}, \mathbf{e})$. Euthyroid controls $(\mathbf{b}, \mathbf{d}, \mathbf{f})$ were studied before, and at 6 and 12 months after RAI. All values represent the mean of three determinations performed in triplicate and with duplicate cAMP RIAs, as noted in Materials and Methods and Table 2. Exact values are presented in Table 2.

WT cells (Table 3 ). This, plus the complete loss of stimulating TSAb activity in the Mc1 +2 and Mc2 chimeras, suggested that TSHR residues $261-370$ are not involved in the epitope for these TSAbs.

\section{Blocking TSBAbs}

To characterize the blocking activity of the IgG of patients with transient hypothyroidism, IgGs prepared at the time of hypothyroidism were incubated with purified bTSH (1 $\mathrm{mU} / \mathrm{mL}$ ) in $\mathrm{WT}, \mathrm{Mc} 1+2$, and $\mathrm{Mc} 2 \mathrm{CHO}$ cells or with a stan- dard TSAb in CHO cells with the Mc4 chimera (Table 4). During transient hypothyroidism, the ability of the IgG to inhibit the stimulatory activity of TSH was lost in 10 patients when their IgG was incubated with $\mathrm{Mc1}+2$ cells and in 8 patients when their IgG was incubated with Mc2 cells (Table 4 , starred, $p<0.001$ and $<0.05$, respectively). The ability of the 10 TSBAb-positive IgG to inhibit the stimulatory activity of Graves' IgG was also lost in Mc4 cells $(p<0.001)$. This pattern is characteristic of a TSBAb that has its functional epitope directed against residues $90-165$ of the N-terminus of the TSHR extracellular domain as well as TSHR residues 


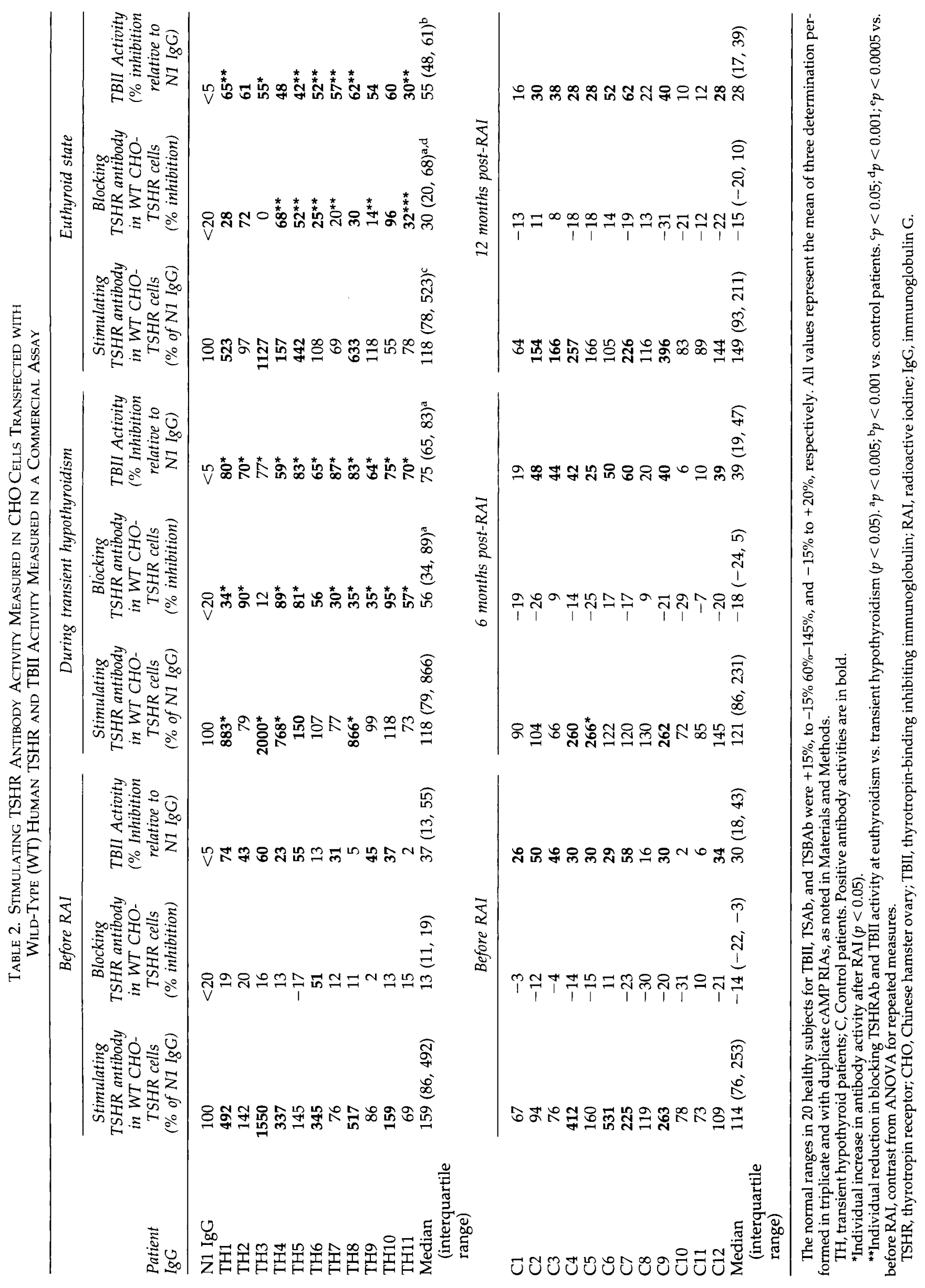


Table 3. Stimulating TSHR Antibody Activity before RAi Measured in CHO Cells Transfected with Wild-TyPe (WT) Human TSHR OR THE MC2, MC1 +2, AND MC4 TSHR/LH CGR CHIMERAS

\begin{tabular}{|c|c|c|c|c|}
\hline $\begin{array}{l}\text { Patient } \\
\operatorname{IgG}\end{array}$ & $\begin{array}{c}\text { Stimulating } \\
\text { TSHR antibody } \\
\text { in WT CHO-TSHR } \\
\text { Cells } \\
(\% \text { of N1. IgG) }\end{array}$ & $\begin{array}{c}\text { Stimulating TSHR } \\
\text { antibody in } \\
M c 1+2 \text { CHO-TSHR } \\
\text { Cells* } \\
(\% \text { of N1. IgG) }\end{array}$ & $\begin{array}{c}\text { Stimulating } \\
\text { TSHR antibody } \\
\text { in Mc2 CHO-TSHR } \\
\text { Cells* } \\
\text { (\% of N1. IgG) }\end{array}$ & $\begin{array}{c}\text { Stimulating } \\
\text { TSHR antibody } \\
\text { in Mc4 CHO-TSHR } \\
\text { Cells } \\
\text { (\% of N1. IgG) }\end{array}$ \\
\hline N1 IgG & 100 & 100 & 100 & 100 \\
\hline $\mathrm{TH} 1{ }^{\circ}$ & 492 & $98^{*}$ & $78^{*}$ & 252 \\
\hline $\mathrm{TH} 2$ & 141 & 86 & 107 & 128 \\
\hline TH3 & 1550 & $73^{*}$ & $86^{*}$ & 1257 \\
\hline TH4 & 337 & $54^{*}$ & $112^{*}$ & 286 \\
\hline TH5 & 145 & 67 & 104 & 112 \\
\hline TH6 & 345 & $78^{*}$ & $108^{*}$ & 301 \\
\hline TH7 & 76 & 93 & 96 & 62 \\
\hline TH8 & 517 & $108^{*}$ & $86^{*}$ & 378 \\
\hline TH9 & 86 & 98 & 78 & 76 \\
\hline TH10 & 159 & $86^{*}$ & $103^{*}$ & 136 \\
\hline TH11 & 69 & 97 & 87 & 62 \\
\hline $\begin{array}{l}\text { Median } \\
\text { (interquartile } \\
\text { range) }\end{array}$ & $159(86,492)$ & $86(73,98)$ & $96(86,107)$ & $136(76,301)$ \\
\hline $\mathrm{C} 1$ & 67 & 60 & 60 & 56 \\
\hline $\mathrm{C} 2$ & 94 & 76 & 67 & 86 \\
\hline $\mathrm{C} 3$ & 76 & 70 & 68 & 70 \\
\hline $\mathrm{C} 4$ & 412 & $68^{*}$ & $62^{*}$ & 380 \\
\hline $\mathrm{C} 5$ & 160 & $77^{*}$ & $60^{*}$ & 150 \\
\hline C6 . & 531 & $70^{*}$ & $64^{*}$ & 389 \\
\hline $\mathrm{C} 7$ & 225 & $62^{*}$ & $68^{*}$ & 187 \\
\hline C8 & 119 & 73 & 62 & 108 \\
\hline $\mathrm{C} 9$ & 263 & $78^{*}$ & $70^{*}$ & 245 \\
\hline $\mathrm{C} 10$ & 78 & 70 & 61 & 70 \\
\hline $\mathrm{C} 11$ & 73 & 77 & 67 & 68 \\
\hline $\mathrm{C} 12$ & 109 & 59 & 69 & 87 \\
\hline $\begin{array}{l}\text { Median } \\
\text { (interquartile } \\
\text { range) }\end{array}$ & $114(76,253)$ & $70(63,76)$ & $65(61,68)$ & $97(70,230)$ \\
\hline
\end{tabular}

$\mathrm{Mc} 1+2$ and Mc2 cells were responsive to TSH, similar to wild-type cells, as previously described (9-13, 15-17). TH, transient hypothyroid patients; C, control patients. All values represent the mean of three determinations performed in triplicate and with duplicate cAMP RIAs, as noted in Materials and Methods. Positive antibody activities are in bold. * values with significant losses by comparison to wild-type values $(p<0.05)$. Median values of TSHR antibody activity measured in different cells lines were similar between two groups.

TSHR, thyrotropin receptor; RAI, radioactive iodine; CHD, Chinese hamster ovary; LH/CGR, lutropin/choriogonadotropin receptor.

261-370 in 8 patients. In 2 patients who lost their inhibitory activity in Mc1 +2 cells but retained inhibitory activity in Mc2 cells, the functional TSBAb epitope is directed against the residue 9-90 of the $\mathrm{N}$ terminus of the TSHR extracellular domain as well as TSHR residues 261-370.

At euthyroidism, the activity of the blocking TSBAb in WT cells significantly decreased in eight patients $(p<0.001)$, remained similar in two, and slightly increased in one subjects (Fig. 1 Table 2). The activity of the two patients with blocking action in Mc2 cells also decreased (patient 2, from $39 \% \pm$ $6 \%$ to $25 \% \pm 10 \%$; patient 10 , from $70 \% \pm 11 \%$ to $21 \% \pm$ $16 \%$ ). Similar to the time at hypothyroidism, no inhibitory activity was observed with any of the IgG at euthyroidism when inculated in Mc1 +2 and Mc4 cells. These results suggested that there was no change in the TSBAb epitope even with the change in hormonal status of the patients.

\section{Discussion}

Hypothyroidism is the most common result of RAI therapy for thyrotoxicosis. With graded doses of ${ }^{131}$ I therapy given ac- cording to the thyroid gland size and activity, the incidence of hypothyroidism in the first year is $10 \%$. Thereafter, a $3 \%$ annual cumulative incidence of hypothyroidism is seen due to chronic gradual thyroid atrophy (21). Among those who develop early and permanent hypothyroidism, $80 \%-85 \%$ develop the disease as a function of the dose of ${ }^{131}$ I, i.e., because of higher or ablative doses resultant from our inability to calculate the exact response to RAI in different individuals. Onethird of U.S. thyroidologists considered hypothyroidism as the desired end point of RAI therapy because they believe this would avoid the risk of recurrent thyrotoxicosis and is also an easier management problem (22). This is, however, controversial because it has the net effect of treating one disease by creating a second, with its own attendant complications and risks. This report does not attempt to address this complicated issue, but rather focuses on the $10 \%$ to $15 \%$ of RAI patients develop transient, rather than permanent hypothyroidism, and do not require life-long $\mathrm{T}_{4}$ replacement therapy. We questioned whether the basis for this might be the development of an unusual subtype of TSHR antibodies. 
Table 4. Blocking tShrab Activity of Patients with Transient Hypothyroidism (TH) Measured in CHO Cells TRANSFected With Wild-Type (WT) Human TSHR or THE Mc2, Mc1 +2, AND Mc4 TSHR/LH CGR CHIMERAS

\begin{tabular}{|c|c|c|c|c|c|}
\hline \multirow[b]{2}{*}{$\begin{array}{l}\text { Patient } \\
\operatorname{IgG}\end{array}$} & \multicolumn{5}{|c|}{ Before RAI } \\
\hline & $\begin{array}{c}\text { TSH Blocking } \\
\text { TSHRAb Activity } \\
\text { in WT CHO- } \\
\text { TSHR Cells } \\
\text { (\% Inhibition) }\end{array}$ & $\begin{array}{c}\text { Graves' IgG } \\
\text { Blocking TSHRAb } \\
\text { Activity in WT } \\
\text { CHO-TSHR Cells } \\
(\% \text { Inhibition })\end{array}$ & $\begin{array}{c}\text { TSH Blocking } \\
\text { TSHRAb Activity } \\
\text { in Mc1+2 } \\
\text { CHO-TSHR Cells } \\
\text { (\% Inhibition) }\end{array}$ & $\begin{array}{c}\text { TSH Blocking } \\
\text { TSHRAb Activity } \\
\text { in Mc2 } \\
\text { CHO-TSHR Cells } \\
\text { (\% Inhibition) }\end{array}$ & $\begin{array}{c}\text { Graves' IgG } \\
\text { Blocking TSHRAb } \\
\text { Activity in Mc4 } \\
\text { CHO-TSHR Cells } \\
\text { (\% Inhibition) }\end{array}$ \\
\hline N1 IgG & $<20$ & $<20$ & $<20$ & $<20$ & $<20$ \\
\hline TH1 & 19 & 14 & 10 & -17 & -25 \\
\hline $\mathrm{TH} 2$ & 20 & -17 & -15 & -13 & 11 \\
\hline $\mathrm{TH} 3$ & 16 & 12 & 10 & -16 & 17 \\
\hline $\mathrm{TH} 4$ & 13 & -11 & 12 & 10 & 14 \\
\hline $\mathrm{TH} 5$ & -17 & -13 & -17 & -2 & 2 \\
\hline TH6 & 51 & 43 & $-21^{*}$ & $-17^{*}$ & $10^{*}$ \\
\hline $\mathrm{TH7}$ & 12 & -10 & 17 & 15 & -10 \\
\hline TH8 & 11 & -26 & -18 & 10 & 7 \\
\hline TH9 & 2 & 7 & 3 & 6 & -11 \\
\hline TH10 & 13 & -11 & -15 & -12 & 10 \\
\hline TH11 & 15 & 10 & 17 & 11 & 15 \\
\hline $\begin{array}{l}\text { Median } \\
\text { (interquartile } \\
\text { range) }\end{array}$ & $13(11,19)$ & $-10(-13,12)$ & $3(-17,12)$ & $-2(-16,10)$ & $10(-10,14)$ \\
\hline N1 IgG & $<20$ & $<20$ & $<20$ & $<20$ & $<20$ \\
\hline $\mathrm{TH} 1$ & 34 & 28 & $-10^{*}$ & $-20^{*}$ & $-15^{*}$ \\
\hline TH2 & 90 & 54 & $-5^{*}$ & 39 & $-20^{*}$ \\
\hline TH3 & 12 & 10 & -10 & -25 & -17 \\
\hline $\mathrm{TH} 4$ & 89 & 70 & $-7^{*}$ & $-15^{*}$ & $-8^{*}$ \\
\hline TH5 & 81 & 42 & $-2^{*}$ & $-10^{*}$ & $-17^{*}$ \\
\hline TH6 & 56 & 23 & $-7^{*}$ & $-10^{*}$ & $-17^{*}$ \\
\hline TH7 & 30 & 26 & $10^{*}$ & $-11^{*}$ & $5^{*}$ \\
\hline TH8 & 35 & 28 & $-9^{*}$ & $-10^{*}$ & $-12^{*}$ \\
\hline TH9 & 35 & 26 & $-7^{*}$ & $-12^{*}$ & $-11^{*}$ \\
\hline TH10 & 96 & 70 & $-10^{*}$ & 70 & $7^{*}$ \\
\hline TH11 & 57 & 34 & $-17^{*}$ & $-19^{*}$ & $-10^{*}$ \\
\hline $\begin{array}{l}\text { Median } \\
\text { (interquartile } \\
\text { range) }\end{array}$ & $56(34,89)^{*}$ & $28(26,54)^{*}$ & $7(10,5)^{t t}$ & $-11(-19,-10)^{\dagger}$ & $-12(-17,-8)^{\dagger+}$ \\
\hline
\end{tabular}

All values represent the mean of three determinations performed in triplicate and with duplicate cAMP RIAs, as noted in Materials and Methods. Positive blocking activities are in bold. ${ }^{*}$ values with significant losses by comparison to wild-type values $(p<0.05$ or better). ${ }^{\dagger}, p<0.05 ;{ }^{H}, p<0.001$, median values compared to wild type values. a, $p<0.001$, median values compared to values before RAI.

Our results demonstrate that transient hypothyroidism after RAI in most patients is associated with a significant surge of blocking antibody (TSBAb) activity in association with a significant surge in TBII activity and, more important, that the blocking TSHR antibody has a hybrid functional epitope directed against residues 261-370, as well as residues 90-165 or 9-89 of the TSHR, i.e., against an epitope associated with hypothyroidism in some patients with idiopathic myxedema or Hashimoto's thyroiditis. Because the TSBAb and TBII activities decrease with time, these patients only developed transient, not permanent hypothyroidism.

Previous studies have reported that RAI treatment is associated not only with changes in the level of TSHR antibodies, but also with changes in the characteristics of the antibodies. McGregor et al. (6) reported an increase in TBII after RAI, and that a surge in TBII was associated with a higher chance of post-RAI hypothyroidism. Because TBII and TSAb activities did not correlate with each other in studies of this period (7), the authors of those studies postulated that the discrepancy could be due to blocking antibodies $(6,7)$. Michelangeli et al. (8) subsequently reported that in their pa- tients with hypothyroidism occurring within 6 months of RAI, blocking antibodies were present in $75 \%$ of hypothyroid patients, half of whom had transient hypothyroidism. It was not specifically mentioned whether their patients with transient hypothyroidism had TSAb activity, nor how many had preexisting blocking or TBII antibodies before RAI, nor what type of blocking TSHR antibody was present. Nevertheless, their data suggested that blocking TSAbs played an important role in causing the hypothyroidism in a significant fraction of these patients, whether hypothyroidism was transient or permanent in nature.

In our present series of patients with transient hypothyroidism, only one patient had TSBAb before RAI, but all except one subject were positive for TSBAb at the time of hypothyroidism. Similar to the observation of McGregor et al. (6), all patients had a surge in TBII activity at the time of hypothyroidism. The development of TSBAb activity in association with the surge in TBII activities suggests the two activities are linked and reflect a unique population of thyroid autoantibodies. This would be consistent with previous observations $(6,12,14)$. 
Our findings and those in the report by Michelangeli et al. (8) do not contradict those of Chivato et al. (23). Chivato et al. (23), using a much higher dose of RAI, detected TSBAb in only $29 \%$ of their patients with hypothyroidism. However, the cause of hypothyroidism after high-dose RAI therapy in that series is probably due to radiation destruction of the thyroid in many cases and mostly permanent in nature. In a retrospective study, Yoshida et al. (24) identified blocking antibodies only in patients who developed early permanent hypothyroidism but not late hypothyroidism.

In this report, we extend previous observations by characterizing the blocking TSHR antibodies developing in association with the transient hypothyroidism. The blocking antibodies in our patients exhibited an unusual behavior. In all cases, the blocking antibodies were directed against a hybrid conformational epitope involving the $\mathrm{N}$ - as well as $\mathrm{C}$ terminal parts of the extracellular domain. Thus the majority were directed against residues 90-165 and residues 261-370, because they lost blocking activity in Mc2 cells, where 90-165 were mutated and in Mc4 cells where residues 261-370 are lost. A minority was however directed against residues 9-89 and residues 261-370, because they lost blocking activity in Mc1 +2 but not Mc2 cells as well as in Mc4 cells. The former antibodies can be construed as similar to the type I TBII in Graves' disease as described previously by Watanabe et al. (14), because those lose TBII and blocking activity in Mc2 cells. However, those types of blocking receptor autoantibodies do not appear to affect the ability of a stimulating TSHR antibody to induce hyperthyroidism, only the activity of TSH $(12,14)$. In the present case, the blockers are also directed at the C-terminus, based on the loss of activity in Mc4 chimeras, in which region TBIIs with blocking activity against TSAbs have been described $(12,14)$. No Mc4 data were presented in the Watanabe et al. (14) report. This kind of antibody might be predicted to exhibit conversion activity, wherein anti-IgG could convert the blocker into a stimulator $(12,14)$. Unfortunately due to limited IgG supply in our study, we could not determine the conversion activity of these sera.

Two patients had blocking antibodies that were directed against residues 9-89 of the TSHR similar to some Graves' TBII, termed type II and described previously (12). This kind of Graves' antibody can activate the inositol phosphate signal transduction system. Unfortunately due to limited Ig supply in our study, we could not determine the ability of these IgGs to activate the inositol phosphate or arachidonate signal transduction system $(12,16)$.

The transient appearance of these antibodies together with the character of these antibodies may explain why the hypothyroidism observed in these patients was only transient in nature. Current studies are aimed at further characterizing the blocking TSHR antibodies using monoclonals to see if these activities represent a single antibody preparation or a heterogeneous population. These data will be needed to resolve questions concerned with specific blocking TSHR antibody activities on specific TSAbs, each with defined but potentially different epitopes. In all patients with stimulating TSHR antibodies, the stimulators appeared to have the same characteristics in both control patients and those with transient hypothyroidism, i.e., they had a homogeneous epitope on the N-terminus of the TSHR. Current experiments are being performed to epitope map stimulating TSHR antibodies in patients pre-RAI and post-RAI who develop permanent hypothyroidism to see if this is a unique feature of this group.

In conclusion, we have demonstrated the existence of heterogeneous antibodies present in patients with Graves' disease treated with RAI. The TSAb activities were directed against $\mathrm{N}$-terminal portion of the TSHR extracellular domain and they require residues $90-165$ for activity. Early transient hypothyroidism after RAI was associated with the temporary appearance of blocking antibody activities in most patients. Two kinds of blocking activities were seen, with one having a functional epitope on residues 90-165 of TSHR and another having an epitope involving residues 9-89 of the TSHR, but both have another epitope on residues 261-370. How RAI alters the profile of antithyroid antibodies is uncertain. It is most likely that RAI causes a release of thyroid antigen from the damaged cells, which results in the stimulation of different clones of lymphocytes producing heterogeneous antibodies that exhibit diversity in their ability to increase cAMP and in blocking TSHR binding or activity. The result causes diversity in the clinical course of the patients after RAI treatment.

\section{ACKNOWLEDGMENTS}

The authors wish to thank Mr. S. Yeung and P. Cheung for technical support, and Ms. K. Yu for typing the manuscript. The study is supported by the Endocrine \& Osteoporosis Research Fund, the University of Hong Kong and CRCG Grant, \#10200844.14549. 20600.323.01.

\section{References}

1. Dunn JT, Chapman EM 1964 Rising incidence of hypothyroidism after radioactive iodine therapy in thyrotoxicosis. $\mathrm{N}$ Engl J Med 271:1037-1042.

2. Lundell G, Holm LE 1980 Hypothyroidism following ${ }^{131}$ I therapy for hyperthyroidism in relation to immunologic parameters. Acta Radiol Oncol 6:449-454.

3. Connel JM, Hilditch TE, McCruden DC, Alexander WD 1983 Transient hypothyroidism following radioiodine therapy thyrotoxicosis. Br J Radiol 56:309-313.

4. Wortsman J, McConnachie P, Tahara K, Kohn LD 1998 Thyrotropin receptor epitopes recognized by Graves' autoantibodies developing under immunosuppressive therapy. J Clin Endocrinol Metab 83:2302-2308.

5. Chung HK, Kim WB, Park DJ, Kohn LD, Tahara K, Cho BY 1999 Two Graves' disease patients who spontaneously developed hypothyroidism after antithyroid drug treatment: characteristics of epitopes for thyrotropin receptor antibodies. Thyroid 9:393-399.

6. McGregor AM, McLachlan SM, Rees-Smith B, Hall R 1979 Effect of irradiation on thyroid-autoantibody production. Lancet 2:442-444.

7. Atkinson S, McGregor AM, Kendall-Taylor P, Peterson MM, Smith BR 1982 Effect of radioiodine on stimulatory activity of Graves' Immunoglobulins. Endocrinology 16:537-543.

8. Michelangeli VP, Poon C, Topliss DJ, Colman PG 1995 Specific effects of radioiodine treatment on TSAb and TBAb levels in patients with Graves' disease. Thyroid 5:171-176.

9. Tahara K, Ban T, Minegishi T, Kohn LD 1991 Immunoglobulins from Graves' disease patients interact with different sites on TSH receptor/LH-CG receptor chimeras than either TSH or immunoglobulins from idiopathic myxedema patients. Biochem Biophys Res Commun 179:70-77. 
10. Kim WB, Cho BY, Park HY, Lee HK, Kohn LD, Tahara K, Koh CS 1996 Epitopes for thyroid stimulating antibodies in Graves' sera: a possible link of heterogeneity to differences in response to antithyroid drug treatment. J Clin Endocrinol Metab 81:1758-1767.

11. Kim WB, Chung HK, Lee HK, Kohn LD, Tahara K, Cho BY 1997 Changes in epitopes for thyroid stimulating antibodies in Graves' disease sera during treatment of hyperthyroidism: therapeutic implications. J Clin Endocrinol Metab 82:1953-1988.

12. Kohn LD, Hoffman WH, Tombaccini D, Marcocci C, Shimojo N, Watanabe Y, Amino N, Kohno Y, Hirai A, Tahara K 1997 Characterization of monoclonal thyroid stimulating and thyrotropin binding inhibiting autoantibodies from a Hashimoto's patient whose children had intrauterine and neonatal thyroid disease. J Clin Endocrinol Metab 82:3998-4009.

13. Tahara K, Ishikawa N, Yamamoto $K$, Hirai A, Ito K, Tamura Y, Yoshida S, Saito Y, Kohn LD 1997 Epitopes for thyroid stimulating and blocking autoantibodies on the extracellular domain of the human thyrotropin receptor. Thyroid 7:867-877.

14. Watanabe $Y$, Tahara K, Hirai A, Tada H, Kohn LD, Amino N 1997 Subtypes of anti-TSH receptor antibodies classified by bio- and conversion assays using $\mathrm{CHO}$ cells expressing wild type human TSH receptor or TSH receptor-LH/CG receptor chimera. Thyroid 7:13-20.

15. Chung H-K, Kim WB, Park DJ, Kohn LD, Tahara K, Cho BY 1999 Two Graves' disease patients who spontaneously developed hypothyroidism after antithyroid drug treatment: Characteristics of epitopes for thyrotropin receptor antibodies. Thyroid 9:393-399.

16. Di Cerbo A, Di Paola R, Menzaghi C, De Filippis V, Tahara K, Corda D, Kohn LD 1999 Graves' immunoglobulins activate phospholipase $\mathrm{A} 2$ by recognizing specific epitopes on the TSH receptor. J Clin Endocrinol Metab 84:3283-3292.

17. Grasso YZ, Kim MR, Faiman C, Kohn LD, Tahara K, Gupta MK 1999 Epitope heterogeneity of TSH blocking antibodies in Graves' patients as detected with wild type versus chimeric TSH receptors. Thyroid 9:531-537.
18. Kung AWC, Yau CC, Cheng A 1994 The incidence of ophthalmopathy after radioiodine therapy for Graves' diseasePrognostic factors and the role of methimazole. J Clin Endocrinol Metab 79:542-546.

19. Blomfield GW, Jones JC, MacGregor AG, Miller H, Wayne EJ, Weetch RS 1955 Treatment of thyrotoxicosis with radioactive iodine-Review a 140 cases. Br Med J 2:1223-1229.

20. Goodwin WE 1953 Thyroid gland weight determination from thyroid scintigram with postmortem verification. Radiology 61:88-92.

21. Goolden AWC, Stewart JSW 1986 Long-term results from graded low dose radioactive iodine therapy for thyrotoxicosis. Clin Endocrinol 24:217-222.

22. Wartofsky L, Glinoer D, Solomon B, Nagataki S, Lagasse R, Nagayama Y, Izumi M 1991 Differences and similarities in the diagnosis and treatment of Graves' Disease in Europe, Japan and the United States. Thyroid 1:129-135.

23. Chiovato L, Fiore E, Vitti P, Rocchi R, Rago T, Dokic D, Latrofa F, Mammoli C, Lippi F, Ceccarelli C, et al 1998 Outcome of thyroid function in Graves' patients treated with radioiodine: Role of thyroid-stimulating and thyrotropinblocking antibodies and of radioiodine-induced thyroid damage. J Clin Endocrinol Metab 83:40-46.

24. Yoshida K, Aizawa Y, Kaise N, Fukazawa H, Kiso Y, Sayama N, Hori H, Nakazato N, Tani J, Abe K 1998 Role of thyroidstimulating antibody in patients who developed hypothyroidism within one year after ${ }^{131}$ I treatment for Graves' disease. Clin Endocrinol 48:17-22.

Address reprint requests to: Annie W.C. Kung Department of Medicine University of Hong Kong Queen Mary Hospital Pokfulam Road Hong Kong

E-mail: awckung@hkucc.hku.hk 